\title{
КОМПЕТЕНТНОСТНЫЙ ПОДХОД И ЕГО РЕАЛИЗАЦИЯ НА ЗАНЯТИЯХ ПО ИНОСТРАННОМУ ЯЗЫКУ
}

\section{COMPETENCE APPROACH AND ITS IMPLEMENTATION IN FOREIGN LANGUAGE CLASSES}

\section{S. Chizhikova \\ A. Kolesnikova}

Summary: The main aim of higher professional education is to prepare a qualified and competent specialist who is able to realize their skills and knowledge in the professional and interpersonal spheres. To achieve this goal, the issue of using a competence-based approach both in education and in teaching a foreign language becomes relevant, which gives advantages to the future specialist to be competitive in the modern labor market. A brief overview of the history of the competence approach and its principles is given, as well as the analysis of the key terms "competence» and "competency». This article considers the key competencies that are formed while teaching a foreign language, as well as the ways to implement the competence approach in foreign language classes.

Keywords: competence, competence-based approach, competent, formation of key competencies, foreign language.

\author{
Чижикова Светлана Николаевна \\ к.филол.н., старший преподаватель, Краснодарское \\ высшее военное авиационное училище летчиков \\ arlana.rus@gmail.com \\ Колесникова Анастасия Юрьевна \\ преподаватель, Краснодарское высшее военное \\ авиачионное училище летчиков \\ anastasia_kolesnikovag@mail.ru
}

Аннотация: Основная цель высшего профессионального образования - подготовить квалифицированного и компетентного специалиста, способного реализовать свои умения и знания в профессиональной и межличностной сферах. Для достижения данной цели актуальным становится вопрос об использовании компетентностного подхода как в образовании в целом, так и при обучении иностранному языку, который дает преимущества будущему специалисту быть конкурентно способным на современном рынке труда. В данной статье проведен краткий обзор истории компетентностного подхода и его принципы, анализ ключевых понятий «компетенция» и «компетентность», рассмотрены ключевые компетенции, формирующиеся при обучении иностранному языку, а также способы реализации компетентностного подхода на занятиях по иностранному языку.

Ключевые слова: слова: компетенция, компетентностный подход, компетентный, формирование ключевых компетенций, иностранный язык.

Целью данной работы представить многоплановое исследование компетентностного подхода при обучении иностранному языку и более глубокое изучение коммуникативной компетенции в связи с областью ее применения.

Предмет исследования: формирование ключевых компетенций у обучающихся на занятиях по иностранному языку.

Для реализации поставленной цели необходимо решить следующие задачи:

1. провести краткий обзор истории компетентностного подхода;

2. проанализировать понятия компетентность и компетенция;

3. рассмотреть принципы компетентностного подхода;

4. разобрать формирование ключевых компетенций;

5. выявить способы реализации компетентностного подхода на занятиях по иностранному языку;

Научная новизна исследования заключается в выборе объекта анализа - компетентностный подход и в определении предмета, целей и задач исследования. Материалы и результаты изучения данной темы имеют 
практическое значение для педагогов высших школ.

В качестве гипотезы исследования выдвигается положение о том, что внедрение компетентностного подхода в образовательный процесс способствует формированию у будущего специалиста совокупности компетенций, которые соответствуют требованиям социального заказа и специфики будущей профессии, а также его внутренним возможностям как личности.

Для разработки теоретико-методологических основ применения компетентностного подхода в процессе обучения произведен анализ отечественной и зарубежной научной литературы. Формирование компетентностного подхода начинается в 60-х годах прошлого века в США и имеет свое развитие в английской, французской, немецкой и российской школах, однако своими истоками уходит в эпоху Просвещения. Его возникновение связывают с исследованиями американского лингвиста Ноама Хомского, который ввел понятие компетенция, стремясь разобраться в усвоении языка человеком. Он различал такие понятия как компетенция и употребление, понимая под компетенцией знание, а под употреблением использование языка в определенных ситуациях [14].

В то же время выходит работа Роберта Уайта, в которой содержание данного понятия наполняется личностными составляющими, включая мотивацию. Социолингвисты Р. Уайт и присоединившийся к нему Р. Кэмпбел определяют понятие «коммуникативной компетенции как способности правильно использовать язык в разнообразных социально детерминированных ситуациях» [20]. Вскоре после того, как Н. Хомский ввел термин «компетенция» и определил его сущность в контексте психолингвистических исследований, данный термин стал использоваться и в педагогическом аспекте. Таким образом, в Америке начало формироваться ориентированное на компетенции образование (Competencebased Education - CBE), целью которого было готовить специалистов, способных успешно конкурировать на рынке труда [12].

Компетентностный подход получил свое развитие в российском образовании в начале 90-х годов прошлого столетия в связи с переходом нашей страны в зону единого Европейского пространства высшего образования. Среди отечественного научного сообщества хочется выделить ряд авторов, посвятивших свои работы изучению данного вопроса. К ним относятся: А.А. Вербицкий, И.А. Зимняя, О.Е. Лебедев, А.В. Хуторской, Э.Ф. Зеер, Э.Э. Сыманюк и другие.

Ключевыми понятиями в компетентностном подходе являются компетенция и компетентность. Вводя эти термины, следует разобраться с их трактовками. До сих пор не существует единого понимания этих понятий. Так, А.В. Хуторской определяет компетенцию как заранее заданное требование к уровню образования обучающегося, а компетентность, как владение человеком компетенции, включающей его личное отношение к ней и предмету деятельности. Компетенция, по мнению Э.Ф. Зеер и Э.Э. Сыманюк, это «интегративная целостность знаний, умений и навыков, обеспечивающих профессиональную деятельность, способность на практике реализовывать свою компетентность» [5]. А.А. Вербицкий рассматривает понятия компетентность и компетенция вместе, определяя компетентность как «компетенцию, реализованную на практике» [3]. Таким образом, компетентностный подход представляет собой совокупность компетентности, применяемой для описания конечного результата обучения, и компетенций, то есть фактического владения знаниями, умениями, навыками и жизненным опытом.

Компетентностный подход строится на определенных принципах, которые раскрывают его суть. Основная цель образовательного процесса - развить у обучающихся способности самостоятельно решать проблемы в различных видах деятельности, опираясь на свои знания и собственный опыт. Развивая эту мысль, следует отметить, что данный принцип становится все более актуальным, так как способность принимать решения, быстро реагировать на ситуацию используя свой внутренний потенциал, является неотъемлемой частью нынешней реальности. Целью компетентностного подхода считается сдвиг парадигмы между знаниями и практической деятельностью для эффективного решения определенных задач. Следующий принцип, позволяющий понять сущность компетентностного подхода, заключается в содержании образования, которое включает в себя социальный опыт решения различных проблем. В продолжение сказанному, подчеркнем, что образовательный процесс - это постоянно развивающийся процесс, соответственно его содержимое эволюционирует в зависимости от внешних факторов. Еще одним принципом компетентностного подхода можно отметить оценку образовательных результатов, достигнутых обучающимися на определенном этапе обучения. Комментируя вышеизложенный принцип, обратим внимание на то, что результаты внедрения компетентностного подхода в образовательный процесс не заставляют себя ждать, и мы можем их наблюдать, оценивая высокий уровень компетенций современных специалистов [7].

Одной из задач данного исследования является рассмотреть формирование ключевых компетенций на занятиях по иностранному языку. Согласно В. Хутмахера, существуют разные подходы к тому, что определяют в качестве ключевых компетенций. Их может быть всего две - уметь писать и думать (scriptural thought (writing) и rational thought), или же семь: учение (learning), исследование (searching), думание (thinking), общение (communicating), взаимодействие (cooperating), уметь делать дело, доводить дело до конца (getting things 
done), адаптироваться к себе, принимать себя (adopting oneself) [19]. Б. Оскарссон говорил о ключевых компетенциях, как способности эффективной работы в команде, планирование, решение проблем, творчество, организационное видение и коммуникативные навыки [11].

Хотелось бы отметить, что все виды компетенций, которые мы будем рассматривать далее, являются социальными в широком смысле этого слова, так как они вырабатываются и формируются в социуме, они социальны по своему содержанию, появляются и функционируют в этом социуме в различных видах деятельности человека: личной, учебной и профессиональной [15].

К базовой социально-личностной компетенции, основанной на целях, поставленных общим образованием, можно отвести коммуникативную компетенцию, которая позволяет самореализоваться и приспособиться к условиям современного мира. Это понятие впервые было использовано американским антрополингвистом Д. Хаймсом, который полагал, что для того, кто изучает любой иностранный язык слишком мало приобрести лингвистическую компетенцию, нужно научиться пользоваться языком. Термин коммуникативная компетенция в отечественной науке был впервые употреблен М.Н. Вятютневым для обозначения способности человека общаться в трудовой или учебной деятельности, удовлетворяя свои интеллектуальные запросы [2].

Т.М. Балыхина рассматривает коммуникативную компетенцию как способность средствами изучаемого языка осуществлять речевую деятельность в соответствии с целями и ситуацией общения в рамках той или иной сферы деятельности [1]. Коммуникативная компетенция - это владение сложными коммуникативными навыками и умениями, формирование адекватных умений в новых социальных структурах, знание культурных норм и ограничений в общении, знание обычаев, традиций, этикета в сфере общения, соблюдение приличий, воспитанность, ориентация в коммуникативных средствах, присущих национальному, сословному менталитету и выражающихся в рамках данной профессии [6].

Овладение ключевыми компетенциями обучающимися, а также формирование коммуникативной компетенции, как одной из самых важных компетенций в обучении иностранному языку, как средством общения в рамках занятия, так и средством коммуникации в реальных условиях жизни и профессиональной сфере возможно при соблюдении определенных требований [17]:

1. Дидактические требования, а именно, образовательные задачи должны быть четко сформированы, содержание занятия оптимально определено и наряду с этим необходимо целесообразно подобрать методы, приемы и средства обучения.

2. Психологические требования. Такие требования связанны с определением содержания и структу- ры урока в соответствии с принципами развивающего обучения, организацией познавательной деятельности обучаемых, учета их возрастных особенностей, а также организацией деятельности мышления и воображения обучаемых в процессе формирования новых знаний и умений.

3. Требования к технике проведения занятия. Для достижения наилучшего результата формирования ключевых компетенций по иностранному языку, занятие должно быть эмоциональным и оптимально ритмичным для обучаемых, со сменой видов деятельности. Занятие проходит в атмосфере доброжелательности и творческого труда, обеспечивая активное участие каждого обучаемого.

В основе содержания иностранного языка лежит практическая деятельность и с позиции компетентностного подхода полученные знания важны, но акцентируется внимание именно на способности применить полученные знания на практики для решения проблемы и языковой ситуативной задачи. Другими словами, быть способным установить и реализовать связь между «знанием - умением» и ситуацией. Поэтому развивая ключевые компетенции, используя любой язык как средство общения, мы можем изучать окружающий мир во всех его проявлениях.

Говоря о коммуникативной компетенции, как совокупности языковой, речевой, социокультурной, компенсаторной, учебно-познавательной компетенций, важно рассмотреть, как данные компетенции формируются в условиях занятия по иностранному языку. Так, одной из составляющих коммуникативной компетенции считается языковая компетенция. Она определяется как достижение некоего уровня владения орфографическим, фонетическим, лексическим и грамматическим аспектами речи и способностями использовать языковые средства для построения высказываний. Языковая компетенция формируется в различных видах речевой деятельности, таких как говорение и письмо [4]. Вместе с тем, речевая компетенция рассматривается как развитие коммуникативных умений во всех видах речевой деятельности, таких как говорение, аудирование, чтение и письмо. Языковая и речевая компетенции развиваются при использовании языка как средства коммуникации в письменной и устной форме. Главная задача - преодолеть языковой барьер, свободно и естественно использовать язык, как средство общения в монологической и диалогической речи. Обучаемые должны быть способны определять социальные роли, вести диалоги на различные темы, а также высказывать свое мнение (монологическое высказывание) согласно заданной теме занятия. О сформированности данных компетенций в письменной форме можно говорить, когда обучающийся способен заполнить анкету, резюме, автобиографию, составить эссе [18].

Существенная роль в развитии коммуникативной 
компетенции отводится социально-культурной компетенции, основной задачей которой является приобщение обучающихся к культуре и традициям страны изучаемого языка. Данная компетенция подразумевает то, что при помощи языка передается культурный опыт страны, с учетом исторических изменений, а также нормы речевого поведения в зависимости от коммуникативной ситуации. Формирование социокультурной компетенций на занятиях иностранного языка предполагает обогащение лингвистическими, эстетическими и этическими знаниями о стране изучаемого языка. Одним из способов развития социокультурной компетенции можно считать использование видеоматериалов, которые являются «культурными портретами страны». Благодаря им, обучаемые могут увидеть модели поведения в различных жизненных ситуациях, особенности географического положения и политического строя, достопримечательности страны и их традиции. Просмотр видеоматериалов позволяет обучающимся развивать навыки восприятия речи на слух, слышать особенности речи, произношение и интонационную составляющую носителей языка.

Хотелось бы отметить, что помимо видеоматериалов, для развития социокультурной компетенции целесообразно использовать наглядность на занятиях по иностранному языку. При этом наглядность может использоваться для обогащения знаний о стране изучаемого языка, так и для развития речевой и языковой компетенций. Наглядный материал в совокупности с речевыми моделями, лексическим и грамматическим материалом позволит смоделировать коммуникативные ситуации, нацеленные на развитие устной речи, как основной составляющей коммуникативной компетенции. Данные ситуации стимулируют речевую деятельность обучающихся, побуждают к беседе (диалогу) по содержанию иллюстративного материала, обмену мнений, построению гипотез и домысливания, а также развитию навыков монологической речи [16].

Т.А. Мальковская уточняет цели применения такого задания, как описание изображения при обучении общему иностранному языку (ИЯ) и профессионально ориентированному - авиационному английскому языку (ААЯ): они частично совпадают. По ее мнению, в обоих случаях «изображение стимулирует коммуникативную мотивацию, подталкивает к использованию английского языка» [8, с.6], таким образом, способствует формированию коммуникативной компетенции. Однако описание картинки в ИЯ - это монологическое высказывание на определенную тему, которое включает в себя личное отношение говорящего к предмету, в то время как основная цель такой работы в ААЯ - максимально точно рассказать собеседнику об изображении, чтобы он смог мысленно представить себе картину происходящего, что обусловлено ситуацией профессионального общения. Особенно актуально это в нештатных ситуациях, когда от точности описания ситуации зависит безопасность людей.

Компенсаторная компетенция - это умение восполнять в процессе общения недостаточность знания языка. Представленный вид компетенции предполагает развитие у обучающихся способности и готовности справляться с недостатком знаний, навыков и умений при изучении иностранного языка. Компенсаторная компетенция крайне важна при овладении лексики по специальности. Развитие и формирование компенсаторной компетенции является одним из приоритетных на занятиях иностранного языка, поскольку данные умения помогут обучающемуся выходить из положения в условиях дефицита языковых средств при получении и передачи иноязычной информации, используя вербальные и невербальные формы общение (перефразирование, описание незнакомого слова более знакомыми дефинициями, использование слов общего характера, использование синонимов и др.).

Учебно-познавательная компетенция - знакомство обучающихся с доступными способами и приемами самостоятельного изучения языков и культур с использованием современных технологических средств. Учебнопознавательная компетентность наилучшим образом формируется с помощью метода проектов. Следует отметить, что с точки зрения обучающегося, учебный проект дает ему возможность проявить себя, творчески мыслить, самостоятельно планировать свои действия в сотрудничестве с преподавателем или группой обучаемых, а также добиться результата и показать этот результат другим [12].

Говоря о достоинствах метода проектов при обучении иностранному языку, стоит отметить его влияние на формирование таких важных качеств обучающихся, как коммуникативные, творческие и интеллектуальные умения и навыки, культура общения и толерантность в общении с другими. Обучающиеся развивают умения критически оценивать результаты своего труда и других, работая в команде (в паре, группе). Помимо вышеперечисленных умений, обучающиеся формируют и развивают умения поиска, обработки и интерпретации необходимой информации с использованием современных компьютерных технологий [13].

Таким образом, коммуникативная компетенция является средством, которое необходимо для формирования речевой деятельности в окружающей среде, при помощи языковых, речевых, социально-культурных, компенсаторных, учебно-познавательных навыков и умений.

Опираясь на общее положение федерального государственного стандарта высшего образования, отметим, что при реализации образовательной программы у будущих специалистов по эксплуатации летательных 
аппаратов необходимо формировать универсальные, общепрофессиональные и профессиональные компетенции. Преподавая такие дисциплины как «Иностранный язык» и «Авиационный английский язык», кафедра иностранных языков формирует вышеперечисленные компетенции у обучающихся в полной мере. Прежде всего, две универсальные компетенции: коммуникативную и межкультурного взаимодействия. При этом коммуникативная компетенция реализуется, как способность применять современные коммуникативные технологии, в том числе на иностранном языке для академического и профессионального взаимодействия. В то время как компетенция межкультурного взаимодействия рассматривается, как умение анализировать и учитывать разнообразие культур в процессе межкультурного взаимодействия. Формирование общепрофессиональной компетенции определяется умением использовать в профессиональной деятельности необходимые методические, регламентирующие и справочные документы. К тому же, кафедра способствует формированию профессиональной компетенции, как способности осуществлять взаимодействие со службами, обеспечивающими полеты и органами обслуживания воздушного движения. В учебной программе четко сформулированы все необходимые компетенции, с пояснением того, что нужно знать, уметь и чем нужно владеть, а именно, знать лексический и грамматический минимум для осуществления иноязычного взаимодействия, чтения и перевода текстов по изучаемой тематике. Нужно уметь использовать иностранный язык в ситуациях межличностного и профессионального общения. Владеть надлежит навыками иноязычного общения в рамках изученной тематики, также навыками чтения и перевода текстов на иностранном языке.

Таким образом, развитие языковых и речевых навыков и умений считается главным направлением кафедры иностранных языков. Для реализации данного направления мы тщательно подходим к отбору учебнометодического материала, основу которого составляют учебные тексты. Первым критерием к подбору тестов является профессиональная направленность вуза, в нашем случае, военная. Такие тексты знакомят будущих специалистов по летной эксплуатации и применении авиационных комплексов с их специальностью и постепенно погружают будущих летчиков в их профессию, в том числе и на иностранном языке. Ввиду того, что мы, как преподаватели, на протяжении всего курса обучения иностранному языку развиваем у обучающихся умения и навыки использовать изучаемый язык как средство общения, то учебные тексты должны быть аутентичными. Поясняя данный критерий отбора текстов отметим, что под аутентичным текстом понимается оригинальный текст, взятый из иностранного источника и изначаль- но не предназначенный для использования в учебный целях. Также, при отборе текстов следует учитывать уровень языковой и профессиональной подготовки обучающихся. Работе с тестом на практических занятиях по иностранному языку отводится значительное время, так как чтение способствует развитию различных видов коммуникативной деятельности и выполняет такие функции как практическое использование иностранного языка, средство изучения языка и культуры, средство образовательной и информационной деятельности.

Овладение устной коммуникацией начинается с аудирования, которое считается базовой составляющей общения. Навык аудирования отрабатывается на занятиях последовательно, в зависимости от курса обучения и темы. Так обучающиеся на первом курсе развивают данный навык на основе звуков или слов, небольших предложений в потоке речи аудиозаписей. Далее, с течением времени обучающиеся учатся развивать аудитивные навыки на основе небольших отрывков с выполнением заданий к нему. На втором курсе обучающиеся продолжают работать с аудитивным материалом, при этом прослушивая или просматривая отрывки, длительность которых может составлять до 1,5-2 минут. Наиболее типичные задания для этого этапа работы с текстом: прослушать текст и вставить пропущенные слова в предлагаемых предложениях / закончить следующие предложения / сказать, о чем в нем говорилось / заполнить таблицу / выполнить тестирование с множественным выбором. Работа с аудиоматериалом направленна на осмысление и понимание информации, развитие речевой компетенции, смысловой переработки полученной информации [9].

Еще одним средством реализации компетентностного подхода на занятиях по иностранному языку является деловая игра. Она используется при обучении и контроле и нацелена на развитие речемыслительной деятельности обучающихся. Деловая игра помогает развивать языковые и речевые навыки, а также моделирует ситуации профессиональной коммуникации и способствует отработке поведенческих моделей, типичных для будущей трудовой деятельности. Во время проведения деловой игры язык служит инструментом, который помогает решать профессиональные и коммуникативные задачи.

Исходя из вышеизложенного, можно сделать вывод, что занятия по иностранному языку дают большую возможность для реализации компетентностного подхода, формирования и развития ключевых компетенций, которые позволят обучающимся в реалиях современного мира применять полученные знания и умения для реализации поставленных задач в профессиональной сфере. 


\section{ЛИТЕРАТУРА}

1. Балыхина Т.М. Словарь терминов и понятий лингводидактической теории ошибки / Т.М. Балыхина. - М.: Изд-во РУДН, 2006. - 195 с.

2. Бочарникова М.А. Понятие «коммуникативная компетенция» и его становление в научной среде / М.А. Бочарникова. // Молодой ученый. - 2009. - №8 (8). - C. 130-132. - URL: https://moluch.ru/archive/8/566/ (дата обращения: 11.01.2021).

3. Вербицкий А.А. Личностный и компетентностный подходы в образовании: проблемы интеграции. - М.: Логос, 2009. - 334 с.

4. Дробинина Ю.С. Развитие навыков языковой компетенции при подготовке к единому государственному экзамену по английскому языку / Ю.С. Дробинина, Ю.Г. Киктева, М.А. Таранова. // Молодой ученый. - 2018. - № 31 (217). - С. 93-96. - URL: https://moluch.ru/archive/217/52272/ (дата обращения: 08.01.2021).

5. Зеер Э.Ф., Сыманюк Э.Э. Компетентностный подход к модернизации профессионального образования // Высшее образование в России. - №4, 2005. С. 23-30.

6. К Куницына В.Н., Казаринова Н.В., Погольша В.М. Межличностное общение. - СПб. [и др.]: Питер, 2001. - 544 с.

7. Лебедев 0.Е. Компетентностный подход в образовании // Школьные технологии. - 2004. - № 5. - С. 3-12.

8. Мальковская Т.А. Использование изображений в языковых и речевых упражнениях для развития устной речевой компетенции в рамках дисциплины «Авиационный английский язык» // Научно-методический электронный журнал «Концепт». - 2016. - № S7. - C. 39- 45. - URL: http://e-koncept. ru/2016/76089.htm (дата обращения: 20.01.21).

9. Науменко Н.П., Чижикова С.Н. Требования к отбору аудиоматериала и этапы работы с ним. В сборнике: Теоретический и практический потенциал современной науки. сборник научных статей. Москва, 2019. С. 171-175.

10. Нефедова Л.А., Ухова Н.М. Развитие ключевых компетенций в проектном обучении // Школьные технологии. - 2006. - № 4. - С. 61.

11. Оскарссон Б. Базовые навыки как обязательный компонент высококачественного профессионального образования / Оценка качества профессионального образования. Доклад 5 / Под общ. ред. В.И. Байденко, Дж.Ван Затворта, Европейский фонд подготовки кадров (ЕФО). Проект ДЕЛФИ. - М., 2001.

12. Разуваева Т.А. Компетентностный подход к образованию: краткий теоретический анализ // Вестник Костромского государственного университета им. Н.А. Некрасова. 2010. Т. 16. № 1. С. 266-269.

13. Рябова Т.В. Метод проектов как средство формирования коммуникативной компетенции при обучении иностранному языку в неязыковом вузе // Научно-методический электронный журнал «Концепт». - 2020. - № 10 (октябрь). - C. 89-101. - URL: http://e-koncept.ru/2020/201075.htm. (дата 0бращения: 24.01.21).

14. Хомский Н. Аспекты теории синтаксиса. — М., 1972 (англ. 1965).

15. Хуторской А.В. Ключевые компетенции и образовательные стандарты // Интернет-журнал «Эйдос». - 2002. - С. 58-64.

16. Чижикова С.Н., Колесникова А.Ю. Использование иллюстрированной наглядности при обучении говорению на иностранном языке // Евразийский Союз Ученых (ЕСУ). - 2020. - № 4 (73). - С. 43-48.

17. Шакирова А.А. Принципы обучения иностранному языку // Современные проблемы науки и образования. - 2015. - № 1-1. - URL: https://scienceeducation.ru/ru/article/view?id=18324 (дата обращения: 04.02.21)

18. Шумилова Е.А. Концепция формирования социально-коммуникативной компетентности будущих педагогов в вузе: монография. Челябинск: Дитрих, 2011. - C. 20-23.

19. Hutmacher Walo. Key competencies for Europe / Report of the Symposium Berne, Switzerland 27-30 March, 1996. Council for Cultural Co-operation (CDCC) / Secondary Education for Europe Strasburg, 1997. - URL: https://files.eric.ed.gov/fulltext/ED407717.pdf

20. White R.W. Motivation Reconsidered: the Concept of Competence // Psychol. Rev. - 1959. - Vol. 66, N 5. - P. $297-332$.

(c) Чижикова Светлана Николаевна (arlana.rus@gmail.com), Колесникова Анастасия Юрьевна (anastasia_kolesnikovag@mail.ru).

Журнал «Современная наука: актуальные проблемы теории и практики» 